\title{
Paul Siffert Receives Woody Award
}

The Woody Award has evolved as an informal yet prized recognition of outstanding volunteer service to MRS. Its name derives from the heroic accomplishments achieved by C.W. ("Woody") White during his presidency of MRS in 1984. Generally presented at a Council dinner, the award has come to symbolize the recognition of services, above and beyond all normal expectations, which have made a major contribution to the success of the Materials Research Society.

During the awards ceremonies at the 1989 Fall Meeting in Boston, MRS Councillor Elton N. Kaufmann announced this year's decision to depart somewhat from recognizing service strictly to MRS per se. In recognition of extraordinary leadership in the founding and nurturing of the European Materials Research Society, Kaufmann presented the 1989 Woody Award to Paul Siffert of the Centre de Recherches Nucléaires, Strasbourg, France:

"This evening we honor an individual who has played the major role in conceiving of, and then implementing, the first MRS-style organization outside the United States.
From one symposium in 1983 run by an ad hoc society called MRS-E, he guided it to a fully and formally established society with two multitopical interdisciplinary meetings per year as well as special workshops, proceedings, and an expanding membership roster. This society, now called E-MRS for European Materials Research Society, covers all of Western Europe."

John Baglin, chair of the MRS Awards Committee, credits Siffert's enthusiastic guidance as the reason E-MRS has, in a few short years, emerged as a vital force in the international materials community. "Its technical meetings have grown; its involvement in materials policy issues in Europe has become significant; its members are enthusiastic, and they share many interests, ambitions and concerns with their MRS counterparts," said Baglin. "Paul's tireless efforts in propelling E-MRS to its present position of success, as its founding president, exemplify the kind of service for which the Woody Award was created-a selfless dedication to the advancement of materials research."

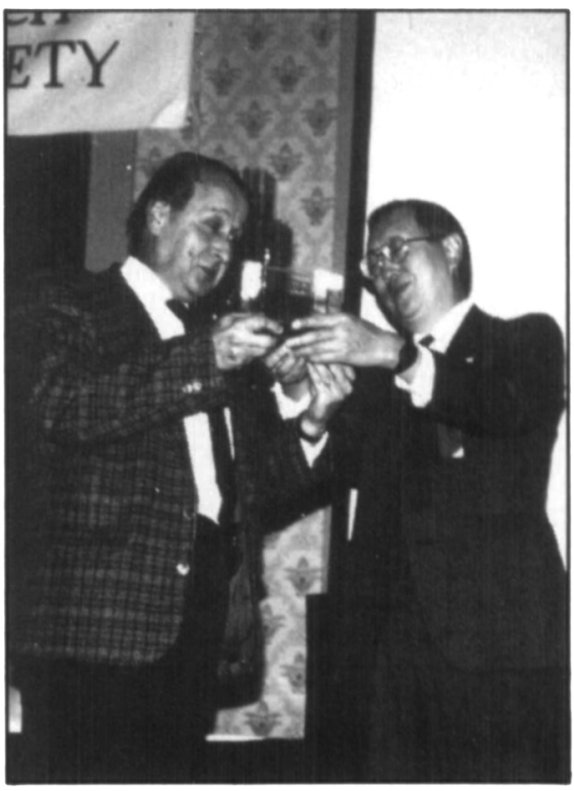

Paul Siffert (left) receives the Woody Award from 1989 MRS President Bob Chang.

\section{Graduate Student Award Winners Honored at Fall Meeting}

MRS honored 13 Graduate Student Award winners at the 1989 MRS Fall Meeting. Starting with this meeting a new procedure was launched for selecting the winners. From the many applications received, 25 finalists were chosen before the meeting. At the meeting each finalist was required to give a 10 -minute presentation on his/her symposium paper at one of five simultaneous student award sessions. The special sessions were held at noon during the second day of the meeting and were open to all meeting attendees. Three judges participated in each award session and gave their recommendations to the MRS Awards Committee. Overall the judges were very impressed with the quality of the student presentations. Each winner received a plaque and a $\$ 250$ travel grant. All 25 finalists received a waiver of their meeting registration fee and a oneyear membership in MRS. Awards Committee Chair John Baglin was very happy with the new procedure and congratulated Subcommittee Chair Kathy Taylor for her thorough planning that made this exciting event run so smoothly.

The 1989 Fall Meeting Graduate Student
Award winners are:

Terry Lynn Alford, Cornell University, (Paper A2.8) "Ion-Beam Synthesis of Buried Yttrium Silicide."

John F. Ankner, University of Illinois, (Paper J2.4) "Neutron Reflectivity Study of GD-Y Interface."

Hilary L. Hampsch, Northwestern University, (Paper Q13.6) “Second Order Nonlinear Optics and Polymer Physics of Corona Poled Polymer Films."

Arun Inam, Rutgers University, (Paper M11.11) "Josephson Weak-Links Fabricated from Heteroepitaxial $\mathrm{YBa}_{2} \mathrm{Cu}_{3} \mathrm{O}_{7.2}$ I $\mathrm{PrBa}_{2} \mathrm{Cu}_{3} \mathrm{O}_{7} / \mathrm{YBa}_{2} \mathrm{Cu}_{3} \mathrm{O}_{7}$ Multilayers."

Qiyuan Ma, Columbia University, (Paper M11.9) "Use of Si-YBaCuO Intermixed System for Patterning of Superconducting Thin Films."

Xiangdong Shi, University of Pennsylvania, (Paper Q11.7) "Sound Velocity Studies of the Bechgaard Salts (TMTSF) $\mathrm{ClO}_{4}$ and (TMTSF) ${ }_{2} \mathrm{PF}_{6}$."

Rajiv K. Singh, North Carolina State University, (Paper M3.1) "Pulsed Laser Technique for Deposition of Superconducting Thin Films: Deposition Physics and In-Situ Processing."
Leland Scott Swanson, Iowa State University, (Paper Q6.6) "Photoluminescence, ESR, and ODMR Studies of Pristine and Photodegraded Poly(3-Hexylthiophene) Films and Solutions."

Igor Szafranek, University of Illinois at Urbana-Champaign, (Paper G8.3) "Passivation and Light-Induced Reactivation of Acceptors in High-Purity Hydrogenated GaAs."

Lisa Tietz, Cornell University, (Paper C12.6) "The Structure of Interfaces in Oxide Heterojunctions Formed by CVD."

Karen I. Winey, University of Massachusetts, (Paper O5.8) "The Ordered Bicontinuous Double Diamond Structure in Blends of Diblock Copolymer and Homopolymer."

Dan Q. Wu, State University of New York at Stony Brook, (Paper O5.5) "Small Angle X-Ray Scattering on Poly(EthyleneMethacrylic Acid) Lead and Lead Sulfide Ionomers."

Satoshi Yamauchi, Tohoku University, (Paper E4.3) "Plasma-Assisted Epitaxial Growth of ZnSe Films in Hydrogen Plasma." 